\title{
Time Dependent Performance of ITER90H-P Fusion Reactor with Considering D-T and D- ${ }^{3}$ He Fuel
}

\author{
S. N. Hosseinimotlagh*1, S.Kianafraz ${ }^{2}$, S. Ghaderi ${ }^{3}$
}

Accepted $15^{\text {th }}$ August 2014

\begin{abstract}
In thermonuclear fusion research using magnetic confinement, the tokamak is the leading candidate for achieving conditions required for a reactor. An international experiment, ITER is proposed as the next essential and critical step on the path to demonstrating the scientific and technological feasibility of fusion energy. ITER is to produce and study plasmas dominated by self-heating. This would give unique opportunities to explore, in reactor relevant conditions, the physics of $\alpha$-particle heating, plasma turbulence and turbulent transport, stability limits to the plasma pressure and exhaust of power and particles. Our studies show that in the dynamical state physical quantities are dependent on temperature and time .Each has its own specific variations and also at the temperature 70 (Kev) these quantities produce the maximum fusion gain for both of fuels $\mathrm{D}-\mathrm{T}$ and $\mathrm{D}-{ }^{3} \mathrm{He}$ such that their values are equal to 81.311 for $\mathrm{D}-\mathrm{T}$ fuel-and the 0.0429 for $\mathrm{D}-{ }^{3} \mathrm{He}$ at one second after occurring fusion $\mathrm{t}=1 \mathrm{~s}$, respectively.
\end{abstract}

Keywords: Gain, Dynamics, Deuterium, Tritium, Helium.

\section{Introduction}

Motivation for development of fusion for power generation is ample. The world is in dire need of a safe, clean, sustainable source of power. In the future as we see it today, population growth continues its march upward, and energy demand, especially in developing countries, rises with only limited adoption of improvements in conservation and renewable. Tokamak fusion reactor that uses deuterium (D) and tritium (T) as its fuel is one of several types of magnetic confinement devices and a leading candidate for producing fusion energy. Fusion energy is produced by the following reactions:

$\mathrm{D}+\mathrm{T} \rightarrow{ }^{4} \mathrm{He}+\mathrm{n}+17.6 \mathrm{MeV}$

$\mathrm{D}+{ }^{3} \mathrm{He} \rightarrow{ }^{4} \mathrm{He}+\mathrm{p}+18.4 \mathrm{MeV}$

The International Thermonuclear Experimental Reactor (ITER) project is in progress (see figure1), and the primary purposes of this project are demonstrations of controlled ignition, long-pulse burning with steady-state, comprehensive technologies for blanket, superconductive coil and plasma facing wall. The DT burn control is one of the key issues for the ITER tasks. Several types of algorithm for the plasma control were developed, and the performances and applicability of them have been considered [1]. Over the years, the physical and technological feasibility of different methods for controlling the burn condition have been studied [2, 3, and 4] considered: modulation of auxiliary power, modulation of fueling rate and con-trolled injection of impurities. The paper is organized as follows. In Section 2, nonlinear point Kinetic equations governing on the ITER $90 \mathrm{HP}$ fusion reactor for the $\mathrm{D}-\mathrm{T}$ and $\mathrm{D}-{ }^{3} \mathrm{He}$ fuel is described. The reactivity parameter for D-T and D- ${ }^{3} \mathrm{He}$ in two ways (A:Buckey and B:Bocsh Hale) are presented in Section 3.The detailed of numerical calculations for

\footnotetext{
${ }^{1-3}$ Department of Physics, Shiraz Branch, Islamic Azad University, Shiraz, Iran

* Corresponding Author Email: hoseinimotlagh@ hotmail.com

Note: This paper has been presented at the International Conference on Advanced Technology\&Sciences (ICAT'14) held in Antalya (Turkey), August 12-15, 2014.
}

these equations and our obtained results are stated in Section 4.Finally, the conclusions and some suggestions about future work are presented in Section 4.

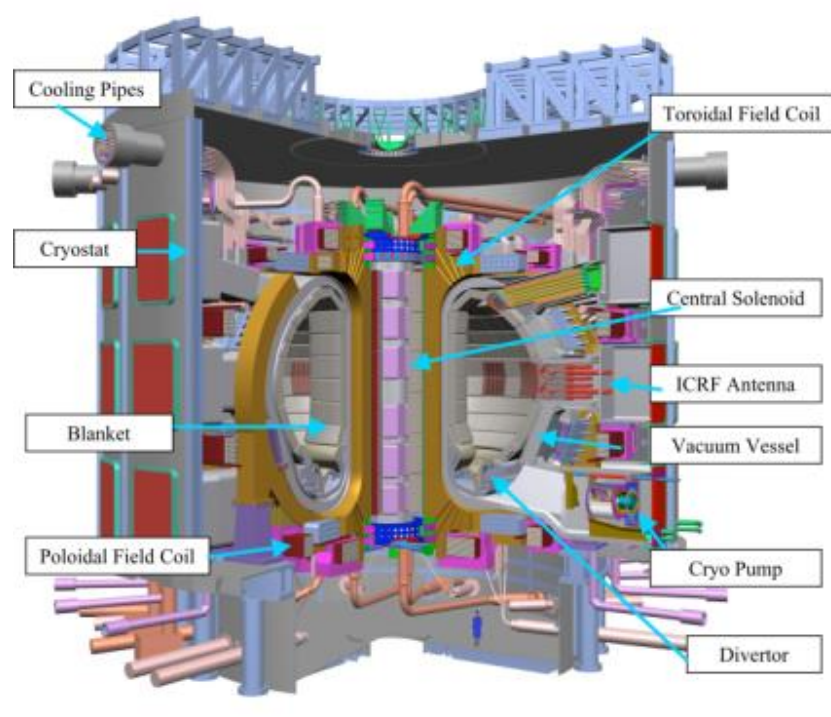

Fig1.Cut away of ITER.

\section{Nonlinear Point Kinetic Equations Governing on the ITER 90 HP Fusion Reactor ITER 90 HP for the D-T and D- ${ }^{3} \mathrm{He}$ Fuels}

In this work, we have used fusion reactor in which approximately particle energy balance equations for two D-T and D- ${ }^{3} \mathrm{He}$ fuels are given by:

\section{2-1- Nonlinear Point Kinetic Equations Governing on the D-T Fuel}

$\frac{\mathrm{dn}_{\alpha}}{\mathrm{dt}}=\frac{-\mathrm{n}_{\alpha}}{\tau_{\alpha}}+\left(\frac{\mathrm{n}_{\mathrm{DT}}}{2}\right)^{2}\langle\sigma \mathrm{v}\rangle_{\mathrm{DT}}$

$\frac{\mathrm{dn}_{\mathrm{DT}}}{\mathrm{dt}}=\frac{-\mathrm{n}_{\mathrm{DT}}}{\tau_{\mathrm{DT}}}-2\left(\frac{\mathrm{n}_{\mathrm{DT}}}{2}\right)^{2}\langle\sigma \mathrm{v}\rangle_{\mathrm{DT}}+\frac{\mathrm{n}_{\mathrm{n}}}{\tau_{\mathrm{d}}}$ 
$\frac{\mathrm{dn}_{\mathrm{n}}}{\mathrm{dt}}=\frac{-\mathrm{n}_{\mathrm{n}}}{\tau_{\mathrm{d}}}+\mathrm{s}$

$\frac{\mathrm{dn}_{\mathrm{I}}}{\mathrm{dt}}=\frac{-\mathrm{n}_{\mathrm{I}}}{\tau_{\mathrm{I}}}+\mathrm{s}_{\mathrm{I}}$

$\frac{\mathrm{dE}}{\mathrm{dt}}=\frac{-\mathrm{E}}{\tau_{\mathrm{E}}}+\mathrm{P}_{\infty}+\mathrm{P}_{\text {ohmic }}-\mathrm{P}_{\mathrm{rad}}+\mathrm{P}_{\mathrm{aux}}$

2-2- Nonlinear Point Kinetic Equations Governing on the D-3He

Fuel

$\frac{\mathrm{dn}_{\alpha}}{\mathrm{dt}}=\frac{-\mathrm{n}_{\alpha}}{\tau_{\alpha}}-2\left(\frac{\mathrm{n}_{\mathrm{D}}{ }^{3} \mathrm{He}}{2}\right)^{2}\langle\sigma \mathrm{v}\rangle_{\mathrm{D}}{ }^{3} \mathrm{He}$

$\frac{\mathrm{dn}_{\mathrm{D}^{3} \mathrm{He}}}{\mathrm{dt}}=\frac{-\mathrm{n}_{\mathrm{D}^{3} \mathrm{He}}}{\tau_{\mathrm{D}}{ }^{3} \mathrm{He}}-2\left(\frac{\mathrm{n}_{\mathrm{D}^{3} \mathrm{He}}}{2}\right)^{2}\langle\sigma \mathrm{v}\rangle_{\mathrm{D}^{3} \mathrm{He}}+\frac{\mathrm{n}_{\mathrm{n}}}{\tau_{\mathrm{d}}}$

$\frac{\mathrm{dn}_{\mathrm{n}}}{\mathrm{dt}}=\frac{-\mathrm{n}_{\mathrm{n}}}{\tau_{\mathrm{d}}}+\mathrm{s}$

$\frac{\mathrm{dn}_{\mathrm{I}}}{\mathrm{dt}}=\frac{-\mathrm{n}_{\mathrm{I}}}{\tau_{\mathrm{I}}}+\mathrm{s}_{\mathrm{I}}$

$\frac{\mathrm{dE}}{\mathrm{dt}}=\frac{-\mathrm{E}}{\tau_{\mathrm{E}}}+\mathrm{P}_{\infty}+\mathrm{P}_{\mathrm{ohmic}}-\mathrm{P}_{\mathrm{rad}}+\mathrm{P}_{\mathrm{aux}}$

In these equations, $\mathrm{n}_{\mathrm{I}}, \mathrm{n}_{\mathrm{n}}, \mathrm{n}_{\mathrm{D} 3 \mathrm{He}}, \mathrm{n}_{\mathrm{DT}}, \mathrm{n}_{\alpha}$ are the alpha particle, deuterium - tritium, deuterium - helium 3 , and the neutral fuel (defined as the number of fuel atoms divided by the core volume) and impurity densities, respectively. $\tau_{\alpha}$ is the confinement time for the alpha particles, $S$ is the refueling rate, $\tau_{\mathrm{DT}}, \tau_{\mathrm{D} 3 \mathrm{He}}$ are the confinement time for ionized fuel particles of $\mathrm{D}, \mathrm{T}$ and ${ }^{3} \mathrm{He}, \mathrm{D}$, respectively. $\tau_{d}$ is the controller lag time ,E is the plasma energy, $\tau_{\mathrm{E}}$ is the energy confinement time, $\tau_{\mathrm{I}}$ is the confinement time for the impurities, $S_{I}$ is the impurity injection rate, $Q_{\alpha}=$ $3.52 \mathrm{MeV}$ is the energy of the alpha particles. $\mathrm{P}_{\alpha}, \mathrm{P}_{\text {aux }}, \mathrm{P}_{\text {rad }}$ , $\mathrm{P}_{\text {ohmic }}, \mathrm{P}_{i}$ and, $\mathrm{P}_{f u}$ are the alpha power, auxiliary power, Ohmic power, radiation loss, the net plasma heating power and fusion power, respectively that are given for $\mathrm{D}-\mathrm{T}$ and $\mathrm{D}-{ }^{3} \mathrm{He}$ fuels in the following:[5]

$P_{\infty D T}=\left(\frac{\mathrm{n}_{\mathrm{DT}}}{2}\right)^{2}\langle\sigma \mathrm{V}\rangle_{\mathrm{DT}} Q_{\alpha D T}$

$P_{\infty \mathrm{D}{ }^{3} \mathrm{He}}=\left(\frac{\mathrm{n}_{\mathrm{D}}{ }^{3} \mathrm{He}}{2}\right)^{2}\langle\sigma \mathrm{v}\rangle_{\mathrm{D}{ }^{3} \mathrm{He}} Q_{\alpha \mathrm{D}{ }^{3} \mathrm{He}}$

$P_{\text {auxDT }}=\frac{E}{\tau_{E}}-\left(\frac{n_{D T}}{2}\right)^{2}\langle\sigma\rangle_{D T} Q_{\alpha D T}-P_{\text {ohmic }}+$

$A_{b D T}\left(n_{D T}+2 n_{\alpha}\right)\left(n_{D T}+4 n_{\alpha}\right) \sqrt{\frac{2 E_{D T}}{3 N_{D T}}}$

$(12-a)$

$P_{a u x D^{3} \mathrm{He}}=\frac{E}{\tau_{E}}-\left(\frac{n_{D^{3} \mathrm{He}}}{2}\right)^{2}\langle\sigma\rangle_{D^{3} \mathrm{He}} Q_{\alpha D^{3} \mathrm{He}}-P_{\text {ohmic }}+$

$A_{b D^{3} \mathrm{He}}\left(n_{D^{3} \mathrm{He}}+2 n_{\alpha}\right)\left(n_{D^{3} \mathrm{He}}+4 n_{\alpha}\right) \sqrt{\frac{2 E_{D^{3} \mathrm{He}}}{3 N_{D^{3} \mathrm{He}}}}$

$E_{i}, N_{i}$ are the total energy and density for (i=DT, $\left.{ }^{3} \mathrm{He}\right)$ :

$$
E_{D T}=\frac{3}{2} N_{D T} T
$$

$E_{D^{3} \mathrm{He}}=\frac{3}{2} N_{D^{3} \mathrm{He}} T$

$(13-b)$
And

$$
\begin{aligned}
& N_{D T}=2 n_{D T}+3 n_{\alpha D T}+\left(Z_{I}+1\right) n_{I} \\
& N_{D^{3} \mathrm{He}}=2 n_{D^{3} \mathrm{He}}+3 n_{\alpha D^{3} \mathrm{He}}+\left(Z_{I}+1\right) n_{I} \\
& P_{r a d D T}=A_{b D T} \times Z_{e f f D T} n_{e}^{2} \sqrt{T} \\
& P_{r a d D^{3} \mathrm{He}}=A_{b D^{3} \mathrm{He}} \times Z_{e f f D^{3} \mathrm{He}} n_{e}^{2} \sqrt{T}
\end{aligned}
$$

Where

$$
\begin{aligned}
& A_{b D T}=4.85 \times 10^{-37}\left(\frac{W m^{3}}{\sqrt{k e V}}\right) \\
& A_{b D^{3} \mathrm{He}}=5.35 \times 10^{-37}\left(\frac{W m^{3}}{\sqrt{k e V}}\right)
\end{aligned}
$$

The effective charge ( $Z_{\text {eff }}$ ) and electron density $\left(n_{e_{i}}\right)$ for D - T and $\mathrm{D}-3 \mathrm{He}$ are:

$$
\begin{aligned}
& Z_{e f f D T}=\frac{n_{D T}+4 n_{\alpha D T}}{n_{D T}+2 n_{\alpha D T}} \\
& Z_{e f f D^{3} H e}=\frac{n_{D^{3} H e}+4 n_{\alpha D^{3} H e}}{n_{D^{3} H e}+2 n_{\alpha D^{3} H e}} \\
& \mathrm{n}_{\mathrm{eDT}}=\mathrm{n}_{\mathrm{DT}}+2 \mathrm{n}_{\alpha \mathrm{DT}}+\mathrm{Z}_{\mathrm{I}} \mathrm{n}_{\mathrm{I}} \\
& \mathrm{n}_{\mathrm{eD}{ }^{3} \mathrm{He}}=\mathrm{n}_{\mathrm{D}^{3} \mathrm{He}}+2 \mathrm{n}_{\alpha \mathrm{D}^{3} \mathrm{He}}+\mathrm{Z}_{\mathrm{I}} \mathrm{n}_{\mathrm{I}}
\end{aligned}
$$

$\mathrm{Z}_{\mathrm{I}}$ is the atomic number of impurities.

$$
\begin{aligned}
\mathrm{P}_{\text {ohmicDT }} & =\eta_{D T} \mathrm{j}^{2} \\
\mathrm{P}_{\text {ohmicD }}{ }^{3} \mathrm{He} & =\eta_{D^{3} \mathrm{He}} \mathrm{j}^{2}
\end{aligned}
$$

is the plasma current density and $\mathrm{n}$ is electron density such that :

$5 \times 10^{5} \leq j(m A) \leq 1.5 \times 10^{6}$ and $0 \leq n_{e}\left(m^{-3}\right) \leq 14 \times 10^{19}$.

$\boldsymbol{\eta}$ is the Spitzer resistivity in which for $\mathrm{D}-\mathrm{T}$ and are given by: $[8,9]$

$\eta_{D T}=1.03 \times 10^{-4} \times T^{\frac{-3}{2}} \times Z_{e f f D T} \times \ln \left(\frac{T^{\frac{3}{2}}}{\sqrt{3.14 \times z_{\text {effDT }} \times e^{3}} \times \sqrt{n}}\right)$

$(20-a)$

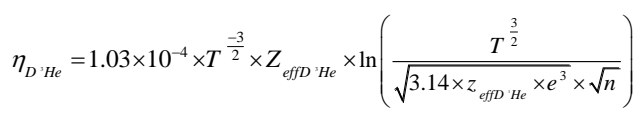

$(20-b)$

Here $\mathrm{T}$ and $\mathrm{e}$ are the electron temperature and charge such that $\mathrm{e}=1.6 \times 10^{-19}(\mathrm{C})$ and :

$P_{i}=P_{\alpha_{i}}-P_{\text {rad }_{i}}+P_{\text {aux }_{i}}+P_{\text {ohmic }_{i}}$

Where $\mathrm{i}=\mathrm{DT}$ and $\mathrm{D} 3 \mathrm{He}$ and

$\mathrm{P}_{\mathrm{fuDT}}=\frac{\left(\mathrm{n}_{\mathrm{DT}}\right)^{2}}{4}<\sigma \mathrm{v}>_{D T} Q_{D T}$

$\mathrm{P}_{\mathrm{fuD}{ }^{3} \mathrm{He}}=\frac{\left(\mathrm{n}_{\mathrm{D}^{3} \mathrm{He}}\right)^{2}}{4}<\sigma \mathrm{V}>_{D^{3} \mathrm{He}} Q_{D^{3} \mathrm{He}}$ 
Also, the gain $(\mathrm{Q})$ of this type of reactor for the $\mathrm{D}-\mathrm{T}$ and $\mathrm{D}-3 \mathrm{He}$ reactions $\mathrm{D}-\mathrm{T}$ are given in the following:

$$
\begin{gathered}
\bar{Q}_{D T}=\frac{\bar{P}_{f u D T}}{\bar{P}_{a u x D T}} \\
\bar{Q}_{D^{3} \mathrm{He}}=\frac{\bar{P}_{f u D^{3} \mathrm{He}}}{\bar{P}_{a u x D^{3} \mathrm{He}}}
\end{gathered}
$$

\section{Reactivity parameter for $\mathrm{D}$ - $\mathrm{T}$ and $\mathrm{D}-3 \mathrm{He}$ fusion reactions}

This paper, presents a strategy for the development of D-3He fusion for terrestrial and space power the approach relies on modest plasma confinement progress in alternate fusion concepts and on the relatively less challenging engineering, environmenta and safety features of a D-3He fueled fusion reactor compared to a $\mathrm{D}$ - $\mathrm{T}$ fueled fusion reactor. The $\mathrm{D}-3 \mathrm{He}$ benefits include fulllifetime materials, reduced radiation damage, less activation absence of tritium breeding blankets, highly efficient direct energy conversion, easier maintenance and proliferation resistance. The main fusion fuels are

$\mathrm{D}+\mathrm{T} \rightarrow{ }^{4} \mathrm{He}+\mathrm{n}+17.6 \mathrm{MeV}$

$\mathrm{D}+{ }^{3} \mathrm{He} \rightarrow{ }^{4} \mathrm{He}+\mathrm{p}+18.4 \mathrm{MeV}$

Also another important parameter is reactivity of D-T and $D^{3}$ Hewhich depends on the temperature.

a) Bucky Reactivity is temperature dependent $(\mathrm{T}(\mathrm{Kev}))$ and is given by: [6]

$\langle\sigma v\rangle_{D T}=\exp \left(\frac{a_{1}}{T^{r}}+a_{2}+a_{3} T+a_{4} T^{2}+a_{5} T^{3}+a_{6} T^{4}\right)$

Here $a_{i}$ and $\mathrm{r}$ are [6] :(for D-T $\left(\mathrm{a}_{1}=2.7764468 \times 10^{1}, \mathrm{a}_{2}=\right.$

$3.1023898 \times 10^{1}, a_{3}=2.7889999 \times 10^{-2}$,

$\mathrm{a}_{4}=5.5321633 \times 10^{-4}, \mathrm{a}_{5}=3.0293927 \times 10^{-6}$,

$\mathrm{a}_{6}=2.5233325 \times 10^{-8}, \mathrm{r}=0.3597$.) and for $\mathrm{D}^{3} \mathrm{He}$

$\left(\mathrm{a}_{1}=2.1377692 \times 10^{1}, \mathrm{a}_{2}=2.5204050 \times 10^{1}\right.$,

$\mathrm{a}_{3}=7.1013427 \times 10^{-2}, \mathrm{a}_{4}=1.937545 \times 10^{-4}$,

$\left.\mathrm{a}_{5}=4.9246592 \times 10^{-6}, \mathrm{a}_{6}=3.9836572 \times 10^{-8}, \mathrm{r}=0.2935\right)$

b) Bosch-Hale reactivity is given by the following formula

$\langle\sigma v\rangle=C_{1} \theta e^{-3 \xi} \sqrt{\xi /\left(m_{r} C^{2} T^{3}\right)}$

$\xi \circ \theta$ and $B_{G}$ are:

$$
\begin{aligned}
& \xi=\left(\frac{\boldsymbol{B}_{G}^{2}}{\mathbf{H} \boldsymbol{\theta}}\right)^{1 / 3} \\
& \theta=T /\left[1-\frac{T\left(C_{2}+T\left(C_{4}+T C_{6}\right)\right)}{1+T\left(C_{3}+T\left(C_{5}+T C_{7}\right)\right)}\right] \\
& \boldsymbol{B}_{G}=\pi \alpha Z_{1} Z_{2} \sqrt{2 m_{r} c^{2}}
\end{aligned}
$$

The constants values of $C_{1}$ to $C_{7}$ and $m_{r} c^{2}(k e V)$ in these equations are [7]:((for D-T: $C_{1}=1.17 \mathrm{E}-09, C_{2}=1.51 \mathrm{E}-02, C_{3}$ $=7.52 \mathrm{E}-02, C_{4}=4.61 \mathrm{E}-03, C_{5}=1.35 \mathrm{E}-02, C_{6}=-1.07 \mathrm{E}-04, C_{7}=$ $\left.1.37 \mathrm{E}-05, m_{r} c^{2}(k e V)=1124656\right)$ and $\left(\right.$ for $\mathrm{D}-{ }^{3} \mathrm{He}: C_{1}=5.51 \mathrm{E}-$
$10, C_{2}=6.42 \mathrm{E}-03, C_{3}=-2.03 \mathrm{E}-03, C_{4}=-1.91 \mathrm{E}-05, C_{5}=1.36 \mathrm{E}-$ $\left.04, C_{6}=0.00 \mathrm{E}+00, C_{7}=0.00 \mathrm{E}+00, m_{r} c^{2}(k e V)=1124572\right)$.

According to the above equations and the data in Table (2-2) we plotted the $\langle\sigma v\rangle$ versus temperature for the fusion reaction of D $\mathrm{T}$ and $\mathrm{D}-{ }^{3} \mathrm{He}$ for both of Bucky and Bosch-Hale formulae.
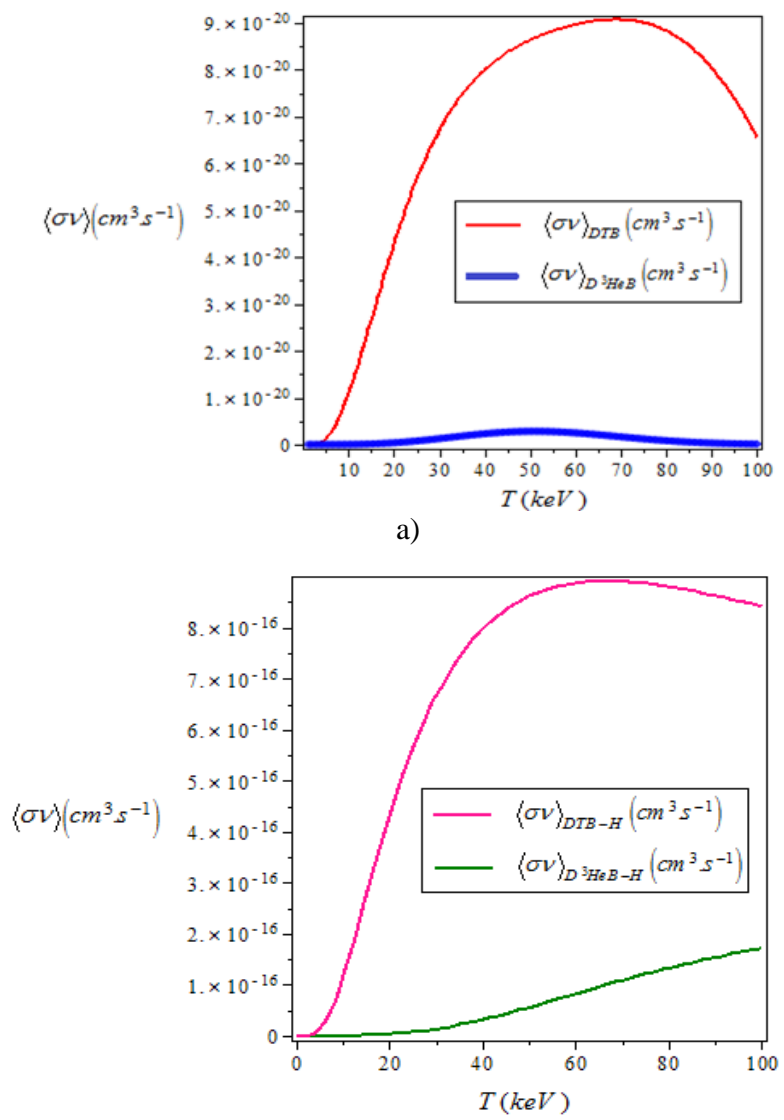

b)

Fig2: Comparison of the graphs of fusion reactions reactivity variations for a) D - T and b) D-3He versus temperature by the two methods, Bucky $\left(\langle\sigma v\rangle_{D T \cdot B}\left(\mathrm{~cm}^{3} \cdot \mathrm{s}^{-1}\right)^{6}\langle\sigma v\rangle_{D^{3} H e \cdot B}\left(\mathrm{~cm}^{3} \cdot \mathrm{s}^{-1}\right)\right.$ and Bosch-Hale $\left(\langle\sigma v\rangle_{D T \cdot B-H}\left(\mathrm{~cm}^{3} \cdot \mathrm{s}^{-1}\right)^{6}\right.$ $\left.\langle\sigma v\rangle_{D^{3} H e \cdot B-H}\left(\mathrm{~cm}^{3} \cdot s^{-1}\right)\right)$

As shown in Figure 2, the reactivity of $\mathrm{D}-\mathrm{T}$ fusion reaction is greater than $\mathrm{D}^{3}{ }^{3} \mathrm{He}$. Because $\langle\sigma v\rangle_{\mathrm{DT}}$ at $70 \mathrm{Kev}$ temperature has a maximum value thus $70 \mathrm{kev}$ is temperature resonance.the value of $\mathrm{D}-\mathrm{T}$ reactivity at this temperature approximately 10 times is greater than $\mathrm{D}^{3}{ }^{3} \mathrm{He}$. By viewing the obtained numerical values and Figure2 we find that the difference between the two ways of calculating reactivity is minimal and since that the method of Bucky is newer than Bosch-Hale in our calculations we use this.

\section{Numerical calculations}

For having information about the time dependent of this type of reactor in terms of the different physical parameters of the system we must solve the nonlinear point kinetic dynamical equations for fusion reactions of $\mathrm{D}-\mathrm{T}$ and $\mathrm{D}-{ }^{3} \mathrm{He}$. And based on the available physical conditions, equations (1) to (10) can be solved as a function of time. The main objective is that from solving these equations we obtain the variations of densities $n_{I}, n_{n}, n_{D^{3} H e}$ $, \mathrm{n}_{\mathrm{DT}}, \mathrm{n}_{\alpha}$, energy density $\mathrm{E}$ and alpha particle power $\mathrm{P}_{\propto}$ auxiliary power $\mathrm{P}_{\text {aux }}$, radiative power loss $P_{\text {rad }}$, Ohmic power $\mathrm{P}_{\text {ohmic }}$, net 
heating power $P$ and fusion power $\mathrm{P}_{\mathrm{fu}}$, for both of D - T and D${ }^{3} \mathrm{He}$ fuel and determine the optimum physical conditions ,fusion gain of choosing fuel.From the numerical solution of equations (1) to (4) for the two fuels D - T and D- ${ }^{3} \mathrm{He}$. In terms of time, variations

of particle densities $\mathrm{n}_{\mathrm{n}}, \mathrm{n}_{\mathrm{D}^{3} \mathrm{He}}, \mathrm{n}_{\mathrm{DT}}, \mathrm{n}_{\alpha}$ and energy are obtained, with respect to time .In which their graphs of variations for comparing are given in figure (3) and (4).

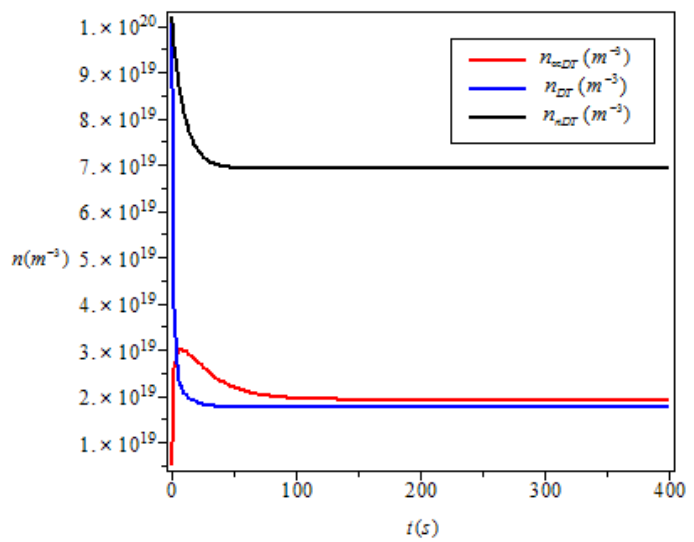

Fig 3:

Comparison of densities time variations of alpha, deuterium and tritium particles for both of fuel $\mathrm{D}-\mathrm{T}$ at temperature $70 \mathrm{Kev}$ in time interval 0400s.

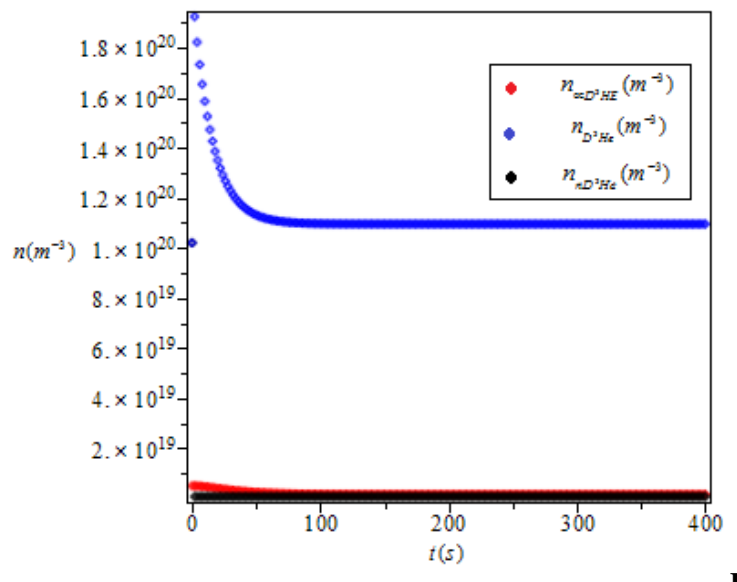

Fig 4: Comparison of densities time variations of alpha, deuterium and tritium particles for both of fuel $\mathrm{D}-{ }^{3} \mathrm{He}$ at temperature $70 \mathrm{Kev}$ in time interval 0400s.

And from solving them, we can obtain numerical values of effective charge of all ions $\left(Z_{\text {eff }}\right)$,electron density, $\left(n_{e}\right)$ ,radiation power loss $\left(P_{\text {rad }}\right)$,total energy $(E)$,auxiliary power $\left(P_{a u x}\right)$ and fusion gain $(Q)$ as a function of time and temperature. Due to the lengthy computations are performed in only temperature 70 (Kev). Form figs (3) and (4) for both reactions D - T and D- ${ }^{3} \mathrm{He}$ can be seen that densities variations both as a function of time have similar behaviors in each reactions. such that in both reactions alpha particles are produced and therefor value of its densities are growing then due to the existence of escape probability and leakage from the system the amounts of them are decreased and after certain time since the system goes to the relative equilibrium the values of densities are fixed. Initially the particle density $\mathrm{D}, \mathrm{T}$, and ${ }^{3} \mathrm{He}$ is declining because due to the fusion of $\mathrm{D}$ with $\mathrm{T}$ and $\mathrm{D}$ with ${ }^{3} \mathrm{He}$ particles of $\mathrm{D}, \mathrm{T}$, and ${ }^{3} \mathrm{He}$ are consumed and their amounts are decreasing and after a certain time the system goes toward a relative balance and the values of densities can be a fixed .Over time, the density of fuel neutral particles in both reactions is declining because in fusion of $\mathrm{D}$ with $\mathrm{T}$ and $\mathrm{D}$ with ${ }^{3} \mathrm{He}$ fuel-neutral are consumed and values of them are going down, and after a certain time the system goes toward an relative equilibrium also density values can be a fixed amount. Since at temperature 70kev which is resonance temperature of $\mathrm{D}-\mathrm{T}$ fusion reaction the maximum number of fusions are occurred. Therefore, we have largest consumption of $\mathrm{D}$ and $\mathrm{T}$ and highest production occurred. In this section, we calculate total energy, auxiliary power, power and fusion gain for ITER90H-p fusion reactor for two fuels D-T and $\mathrm{D}-3 \mathrm{He}$ in terms of time at temperature $70(\mathrm{Kev})$.Also, from equations $(13-a)$, and $(13-b)$ total energy density variations versus time at temperature $70(\mathrm{Kev})$ for both fuel D - T and D-3He are as follows. (See fig.5).

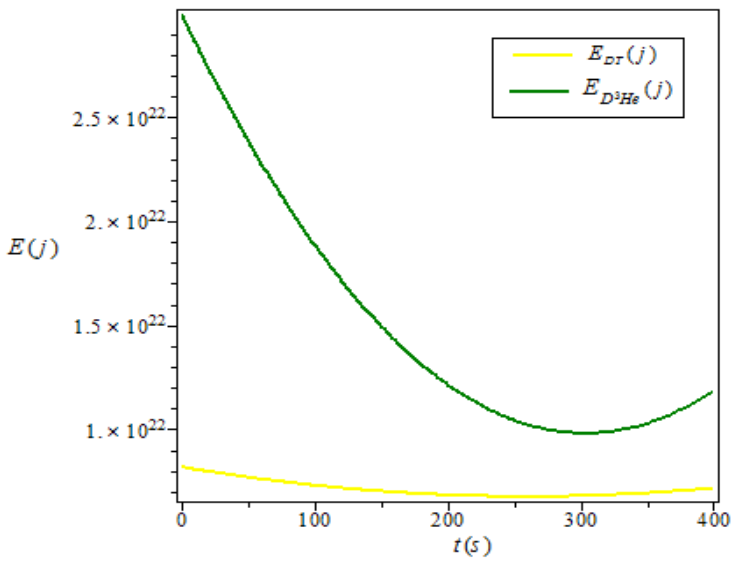

Fig 5: Comparison of the total energy density for DT fuel and D- ${ }^{3} \mathrm{He}$ a temperature $70(\mathrm{Kev})$ in the time range of 0 to 400 seconds

Figs.5 represent that the energy is directly related to temperature so that the temperature increases, the total energy increases. Also total energy of variations for D-T fuel $\left(N_{D T}\right)$ is greater than D${ }^{3} \mathrm{He},\left(N_{D^{3} \mathrm{He}}\right)$ Our calculations show that highest energy is due to $\mathrm{D}-\mathrm{T}$ fusion reaction at the resonance temperature $(70(\mathrm{Kev}))$ .Using equations $(12-a)$, and (12 - b),the diagrams of auxiliary power variations versus time at temperature $70(\mathrm{Kev})$ for both fuel $\mathrm{D}-\mathrm{T}$ and $\mathrm{D}-{ }^{3} \mathrm{He}$ are given in the Figure 6

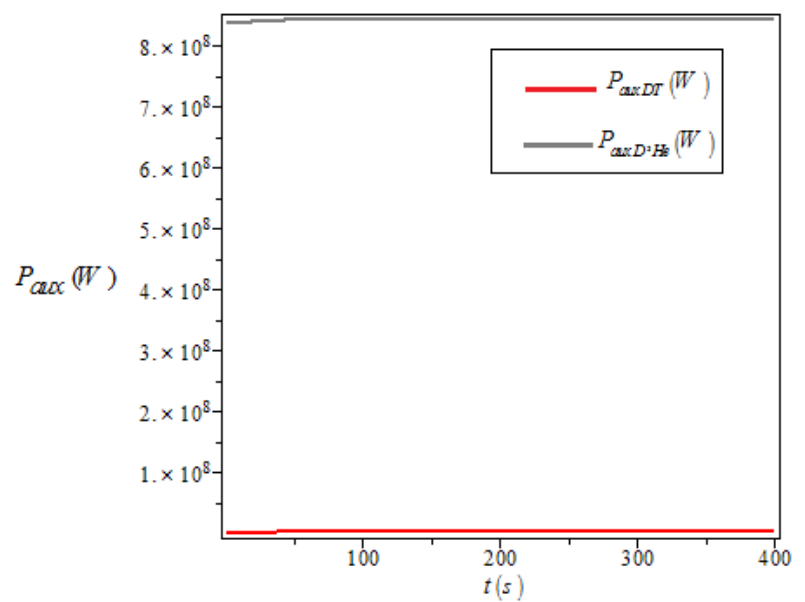

Fig 6: Comparison of auxiliary power for D-T and D-3He fuel in time range of 0 to 400 seconds at temperature $70(\mathrm{Kev})$.

By seeing numerical values at available physical conditions we conclude that auxiliary power of $\mathrm{D}^{3} \mathrm{He}$ is greater D-T. Using equations (22-a), and (22-b) the diagram of fusion power variations versus time at temperature $70(\mathrm{Kev})$ for both fuel $\mathrm{D}-\mathrm{T}$ and $\mathrm{D}-{ }^{3} \mathrm{He}$ are given at Figure 7 . 


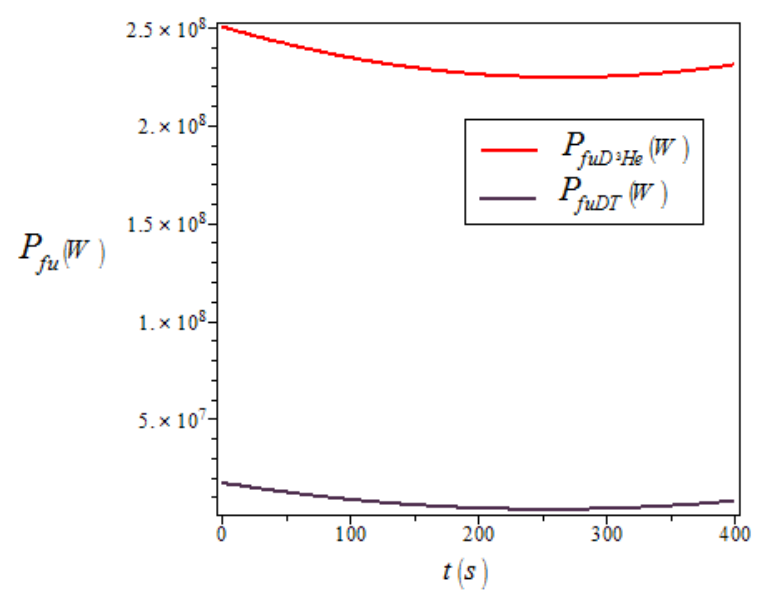

Fig 7: Comparison of fusion power for both of the D-T and D- ${ }^{3} \mathrm{He}$ fusion fuel at temperature $70(\mathrm{Kev})$ in the time range of 0 to $400 \mathrm{~s}$.

From these figures can be seen that time variations of fusion power for D-T fusion fuel at the resonance temperature $70(\mathrm{Kev})$ is more than fusion power at the other temperatures. Because in this temperature we have maximum number of fusion reactions and thus produced energy is maximized. Also we can see that at time variations of fusion power for $\mathrm{D}-{ }^{3} \mathrm{He}$ is lower than D-T.

Also, from equations (23 - a), and (23 - b) graphs of fusion gain variations in terms of time, at temperature $70(\mathrm{keV})$, for both of fuel $\mathrm{D}-\mathrm{T}$ and $\mathrm{D}-{ }^{3} \mathrm{He}$ are as follows( see fig.8.).

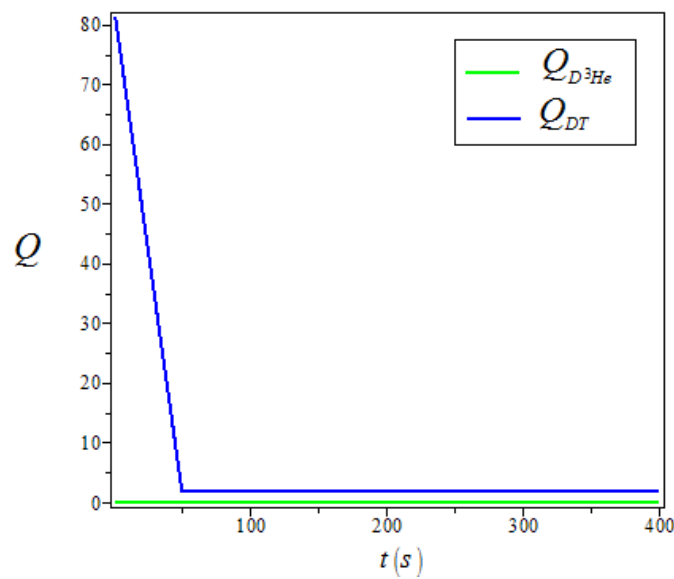

Fig 8: Comparison of fusion gain for D-T and $\mathrm{D}-{ }^{3} \mathrm{He}$ fusion fuel in 70 (Kev) temperatures at range of time 0 to $400 \mathrm{~s}$.

With Comparing the two diagrams of fusion gain for $\mathrm{D}$ - $\mathrm{T}$ and $\mathrm{D}-$ ${ }^{3} \mathrm{He}$, we can conclude that fusion gain of D-T is more greater than $\mathrm{D}-{ }^{3} \mathrm{He}$. Such that at resonance temperature of D-T $(70(\mathrm{Kev}))$ the maximum accessible fusion gain for D-T is about 80 however for is nearly equal to 0.043 . Therefore we recommended that for having high fusion gain in fusion reactor ITER90H-p D - T fuel is used instead of $\mathrm{D}^{-} \mathrm{He}$.

\section{Conclusions}

With studying and analyzing of ITER90H-P fusion reactors and solving the non-linear point kinetic equations governing on the two- fuel D-T and D- ${ }^{3} \mathrm{He}$ at dynamical state, we find that the main quantities in determining the fusion gain are the densities of alpha particles, deuterium, tritium, helium, neutral fuel, electron , fusion energy and the total energy, and density of total particles, the effective charge of all ions, radiative power loss, auxiliary and fusion power ,respectively In order to be commercially competitive, a fusion reactor needs to run long periods of time in a stable burning plasma mode at working points which are characterized by a high $\mathrm{Q}$, where $\mathrm{Q}$ is the ratio of fusion power to auxiliary power. Active burn control is often required to maintain these near-ignited or ignited conditions $(\mathrm{Q}=\infty)$. Although operating points with these characteristics that are inherently stable exist for most confinement scalings, they are found in a region of high temperature and low density. Our studies show that in the dynamical state above quantities are dependent on the temperature and time .Each has its own specific variations and also at the temperature $70(\mathrm{Kev})$ these quantities produce the maximum fusion gain for both of fuels D-T and $\mathrm{D}_{-}{ }^{3} \mathrm{He}$, such that their values are equal to 81.311 for $\mathrm{D}-\mathrm{T}$ fuel-and the 0.0429 for $\mathrm{D}-{ }^{3} \mathrm{He}$ at one second after occurring fusion $\mathrm{t}=1 \mathrm{~s}$, respectively. Fusion using $\mathrm{D}-$ ${ }^{3} \mathrm{He}$ fuel requires significant physics development particularly of plasma confinement in high performance alternate fusion concepts. Countering that cost, engineering development cost should be much less for $\mathrm{D}-{ }^{3} \mathrm{He}$ than $\mathrm{D}-\mathrm{T}$, because $\mathrm{D}-{ }^{3} \mathrm{He}$ greatly ameliorates the daunting obstacles caused by abundant neutrons and the necessity of tritium breeding. D- ${ }^{3} \mathrm{He}$ fusion fueled fusion reactor would also possess substantial safety and environmental advantages

D-T.

\section{References}

[1] O. Mitarai, "Development of the ignition control algorithm with diagnostic sets for an inductive operation in a Tokamak reactor", New Developments in Nuclear Fusion Research, Nova Science Pub. (2006).

[2] J. Mandrekas and W. M. Stacey, "Evaluation of different burn control methods for the international thermonuclear experi-mental reactor", Proceedings of the 13th IEEE/NPSS Symposium on Fusion Engineering, vol.1, pp. 404-7, 1990.

[3] S. W. Haney, L. J. Perkins, J. Mandrekas and W. M.Stacey, Jr., "Active control of burn conditions for the interna-tional thermonuclear experimental reactor", Fusion Technology,vol.18, (no.4), pp. 606-17, Dec 1990.

[4] D. Anderson, T. Elevant, H. Hamen, M. Lisak and H.Persson, "Studies of fusion burn control", Fusion Technology,vol.23, (no.1), pp. 5-41, Jan 1993.

[5] A.V. Eremin , A.A. Shishkin," Fusion D-T and D-D products dynamics for the different fueling scenarios in toroidal magnetic reactors", SSN 0503-1265. Ukr. J. Phys. V. 53, N 5,(2008).

[6] L. M. Hively, "Convenient Computational Forms for Maxwellian Reactivities," Nucl. Fusion, 17, 4, 873 (1977)

[7] H.S.Bosch, G.M.Hale,Nuc.Fusion,32,611(1992)

[8] L. Spitzer, Physics of Fully Ionized Gases Interscience, New York, (1956 )

[9] F. Trintchouk,M. Yamada, H. Ji, R. M. Kulsrud, and T. A. Carter," Measurement of the transverse Spitzer resistivity during collisional magnetic reconnection", PHYSICS OF PLASMAS, VOLUME 10, NUMBER 1, (2003). 